\title{
Importance of Nodal Metastases Location in Pancreatoduodenectomy for Pancreatic Ductal Adenocarcinoma: Results from a Prospective, Lymphadenectomy Protocol
}

\author{
Giuseppe Malleo, MD $\mathrm{PhD}^{1}$ (1) , Laura Maggino, $\mathrm{MD}^{\mathbf{1}}$, Fabio Casciani, $\mathrm{MD}^{\mathbf{1}}$, Gabriella Lionetto, $\mathrm{MD}^{\mathbf{1}}$, \\ Sara Nobile, MD ${ }^{1}$, Gianni Lazzarin, MD $^{1}$, Salvatore Paiella, $\mathbf{M D}^{1}$, Alessandro Esposito, $\mathbf{M D}^{\mathbf{1}}$, \\ Paola Capelli, $\mathrm{MD}^{2}$, Claudio Luchini, $\mathrm{MD}^{2}$, Aldo Scarpa, $\mathrm{MD}^{2}$, Claudio Bassi, $\mathrm{MD}^{1}$, and \\ Roberto Salvia, MD PhD ${ }^{1}$ \\ ${ }^{1}$ Department of Surgery, Dentistry, Gynecology and Pediatrics, Unit of General and Pancreatic Surgery, University of \\ Verona, Verona, Italy; ${ }^{2}$ Section of Pathology, Department of Pathology and Diagnostics, University of Verona, Verona, \\ Italy
}

\begin{abstract}
Background. Implementing a prospective lymphadenectomy protocol, we investigated the nodal yields and metastases per anatomical stations and nodal echelon following upfront pancreatoduodenectomy (PD) for cancer. Next, the relationship between the extension of nodal dissection, the number of examined and positive nodes (ELN/ PLN), disease staging and prognosis was assessed.

Methods. Lymphadenectomy included stations 5, 6, 8a-p, 12a-b-p, 13, 14a-b, 17, and jejunal mesentery nodes. Data were stratified by $\mathrm{N}$-status, anatomical stations, and nodal echelons. First echelon was defined as stations embedded in the main specimen and second echelon as stations sampled as separate specimens. Recurrence and survival analyses were performed by using standard statistics.

Results. Overall, 424 patients were enrolled from June 2013 through December 2018. The median number of ELN and PLN was 42 (interquartile range [IQR] 34-50) and 4 (IQR 2-8). Node-positive patients were $88.2 \%$. The commonest metastatic sites were stations $13(77.8 \%)$ and 14 (57.5\%). The median number of ELN and PLN in the first echelon was 28 (IQR 23-34) and 4 (IQR 1-7). While first-
\end{abstract}

(C) The Author(s) 2022

First Received: 25 August 2021

Accepted: 16 January 2022;

Published Online: 21 February 2022

R. Salvia, MD PhD

e-mail: roberto.salvia@univr.it echelon dissection provided enough ELN for optimal nodal staging, the aggregate rate of second-echelon metastases approached 30\%. Nodal-related factors associated with recurrence and survival were $\mathrm{N}$-status, multiple metastatic stations, metastases to station 14, and jejunal mesentery nodes.

Conclusions. First-echelon dissection provides adequate number of ELN for optimal staging. Nodal metastases occur mostly at stations 13/14, although second-echelon involvement is frequent. Only station 14 and jejunal mesentery nodes involvement was prognostically relevant. This latter station should be included in the standard nodal map and analyzed pathologically.

Lymph node (LN) status is a well-established prognostic factor following pancreatoduodenectomy (PD) for pancreatic ductal adenocarcinoma (PDAC). ${ }^{1}$ The burden of nodal involvement is currently quantified based on the American Joint Committee on Cancer Staging (AJCC) TNM classification, whereby N1 status is defined as 1 to 3 positive LN (PLN) and N2 status as 4 or more PLN. ${ }^{2-4}$ In this framework, we have recently shown that pathologic examination of at least 28 regional LN ensures identification of 4 PLN with a 95\% probability, avoiding underreporting of $\mathrm{N} 2$ patients. ${ }^{5}$ However, the issue of $\mathrm{LN}$ involvement might not be treated by the LN number solely, as the location of nodal metastases possibly impacts on tumor staging and patient prognosis. ${ }^{6,7}$ The extent of lymphadenectomy and the stations that should be removed in PD for PDAC were 
proposed in 2013 by the International Study Group of Pancreatic Surgery (ISGPS). The definition of "standard" dissection included stations 5, 6, 8a, 12b, 12c, 13, 14a-b, and 17 per the Japanese Pancreas Society nomenclature, although there was no general agreement on the exclusion of certain stations (i.e., $8 \mathrm{p}$ and $16 \mathrm{~b} 1){ }^{8}$ An internal discussion followed the ISGPS definition release, and a nodal dissection protocol was established at the unit of pancreatic surgery in Verona, entailing the ISGPS lymphadenectomy with extension to stations $8 \mathrm{p}, 12 \mathrm{a}-\mathrm{b}$, and jejunal mesentery nodes. This was not in contrast with the ISGPS principles, as dissection of stations situated near the "standard" basin and that could be easily incorporated into the resection plane was justified with general agreement. ${ }^{8}$ Following prospective application of this protocol, we herein examined the nodal yields and metastases per anatomical stations and the degree to which the extension of nodal dissection impacts on the number of ELN, PLN, and nodal staging. Finally, the prognostic role of these nodal parameters was investigated.

\section{MATERIALS AND METHODS}

\section{Lymph Node Dissection Protocol and Operative Details}

The institutional lymphadenectomy protocol for was applied to upfront PD for presumed PDAC from June 2013. Dissection included stations 5, 6, 8a-p, 12a-b-p, 13, 14a-b, 17 , and jejunal mesentery nodes per the Japanese Pancreas Society definition (Fig. 1). ${ }^{9}$ Station 16a2-b1 dissection was not routinely practiced, being these nodes sampled for frozen section at the surgeon's discretion when macroscopically enlarged and/or suspicious. Because paraaortic node involvement was considered as distant metastatic disease, the resection was aborted in the instance of positive frozen section. For the purposes of this study, negative station 16a2-b1 samples were not included in the nodal count. The resection phase was performed as previously described. ${ }^{10}$ Superior mesenteric artery (SMA) dissection was generally conducted along its right aspect. Synchronous superior mesenteric vein-portal vein resection was performed in case of macroscopic vascular involvement. Arterial resection was not practiced in the upfront setting.

\section{Pathologic Examination}

All specimens were analyzed by specialized pathologists. The slicing strategy consisted of a bivalve slicing followed by perpendicular slicing $(4 \mathrm{~mm})$. Stations 13 and 17 were examined following orange-peeling and full inclusion in paraffin blocks of peripancreatic soft tissues. Station 14 nodes were examined along the SMA groove. The first jejunal loop mesentery was fully included, and LN were identified microscopically. Other stations removed as distinct specimens were fully included and analyzed. The presence of LNs sliced in halves was always specified to avoid double counting. R-status was defined based on the presence of tumor cells within $1 \mathrm{~mm}$ from any resection margin. Tumors were staged according to the 8th edition of the AJCC manual from its introduction. ${ }^{3}$ For prior

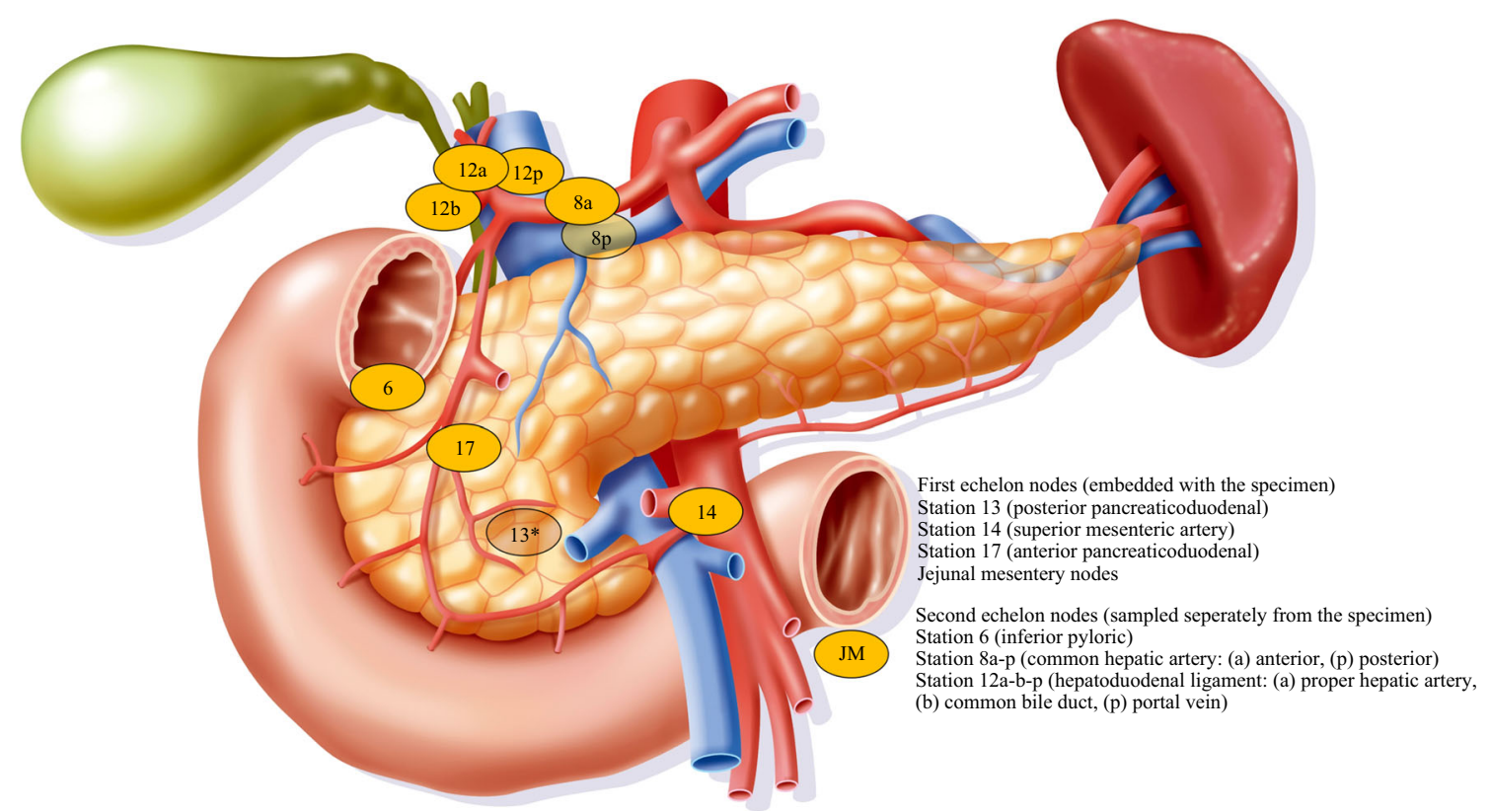

FIG. 1 Institutional nodal dissection (anatomical stations and echelons) during PD for PDAC 
resections, tumors were restaged from the 7 th to the 8 th edition retrospectively.

\section{Exclusion Criteria}

Only patients with conventional PDAC on final pathologic report were considered for the analysis. Other histotypes including cancers arising in the background of an intraductal papillary mucinous neoplasms, acinar cell carcinomas, squamous carcinomas, and rare variants were excluded. Patients receiving multivisceral resection, a macroscopically incomplete resection, and those who died within 90 days from the index operation also were excluded.

\section{Statistical Analysis}

A precision-based approach was used to calculate sample size. Assuming that up to $35 \%$ of the subjects would harbor nodal metastases in stations removed as distinct specimens (based on the aggregate frequency of metastases at stations 6,8 , and 12 in a previous historical series ${ }^{11}$ ), and expecting a per protocol complete nodal dissection in $85 \%$ of cases, the study would require a sample size of 412 patients for estimating the expected proportion with 5\% absolute precision and 95\% confidence. Demographic, clinical, surgical, and pathologic details were prospectively collected in an electronic database. Continuous variables were expressed as medians with interquartile range (IQR). Categorical variables were presented as frequencies with percentages and compared using Chi-square test or Fisher's exact test, as appropriate. Stations embedded in the PD specimen $(13,14 \mathrm{a}-\mathrm{b}, 17$, and jejunal mesentery $\mathrm{LN})$ were defined as first nodal echelon, whereas stations sampled as distinct specimens (5, 6, 8a-p, 12a-b-p-c) were defined as second-echelon nodes. Total nodal yields and PLN per nodal echelon were then analyzed to establish their relative contribution to the staging process. The overall survival (OS) was calculated from the date of PD to the date of last follow-up or death. The recurrence-free survival (RFS) was calculated from the date of PD to the date of first recurrence, defined as the presence of biopsy-proven tumor or assumed based on serum Ca 19.9 levels and cross-sectional imaging studies, in conjunction with clinical picture. Cumulative event rates were calculated using the method of Kaplan and Meier, pairwise differences between survival and recurrence functions were evaluated using the log-rank test. Multivariable Cox regression models adjusted for relevant clinical and pathologic variables were constructed to explore the prognostic significance of noderelated parameters, including the PLN-based system (N1/ $\mathrm{N} 2$ per the current AJCC 8th edition definition), ${ }^{3}$ the number of metastatic stations, nodal echelons, and a LN station-based system. Each model concordance was evaluated using the Harrell's c-statistics. The proportional hazard assumptions were verified. The $p$-values are presented with hazard ratios (HRs) and 95\% confidence intervals (CI), as appropriate. Statistical significance was determined by a $p$ value $<0.05$. Data were analyzed using SPSS software release 25 (SPSS, and IBM company, Armonk, NY), and R-software, version 3.6.3, (Foundation for Statistical Computing, Vienna, Austria, http://www.rproject.org).

\section{RESULTS}

\section{Analysis of Nodal Yields per Anatomical Stations and Nodal Echelons}

In the study period (January 2013 to December 2018), 674 patients underwent PD for pathologically proven conventional PDAC. Of these, 231 patients were not eligible (228 received neoadjuvant therapy and 3 underwent $\mathrm{PD}$ with contiguous organ resection). Of the 443 eligible patients, 19 were excluded ( 7 received R2 resection, 2 had an oligometastatic disease, 10 died within 90 days from surgery). Therefore, the study population consisted of 424 patients (study flowchart in supplementary Fig. 1); their characteristics are displayed in supplementary Table 1 . The median number of ELN was 42 (interquartile range [IQR] 34-50), the median number of PLN was 4 (IQR 2-8). Overall, 374 patients had nodal metastases (88.2\%). Patient characteristics stratified by $\mathrm{N}$-status and nodal echelons are displayed in Table 1. Overall, 248 patients (58.5\%) harbored disease only in the first nodal echelon (stations 13 , 14,17 , and jejunal mesentery nodes), 4 patients $(0.9 \%)$ only in the second echelon (stations $5,6,8,12$ ), and 122 patients $(28.8 \%)$ in both echelons. Therefore, the overall number of patients with metastases in the first and second nodal echelon was $370(87.3 \%)$ and $126(29.7 \%)$ respectively. The median number of ELN and PLN in the first echelon was 28 (IQR 23-34) and 4 (IQR 1-7). The addition of second-echelon nodes increased the median nodal count by 10 ELN (IQR 6-14) and 0 PLN (IQR 0-1), translating in only minor changes to the nodal staging (supplementary Table 2). In particular, 4 patients $(0.9 \%)$ migrated from N0 to $\mathrm{N} 1$ status, 1 patient $(0.02 \%)$ from $\mathrm{N} 0$ to $\mathrm{N} 2$ status, and 13 patients $(3.0 \%)$ from $\mathrm{N} 1$ to $\mathrm{N} 2$ status. The rate of margin-positive resections progressively escalated with increasing nodal status and echelon involvement (both $p<$ 0.001). Nonetheless, $43.1 \%$ of $\mathrm{N} 2$ patients and $38.1 \%$ of those with second echelon involvement received a R0 resection.

The nodal yields per anatomical station, the rate of metastatic involvement, the correlation with nodal staging 
TABLE 1 Demographic, clinical, surgical, and pathologic details of the study population stratified by N-status and nodal echelons

\begin{tabular}{|c|c|c|c|c|c|c|c|}
\hline \multirow[b]{2}{*}{$\begin{array}{l}\text { Parameter } \\
\mathrm{N}(\%)\end{array}$} & \multicolumn{4}{|c|}{ AJCC 8th N-status } & \multicolumn{3}{|c|}{ Site of nodal metastases } \\
\hline & $\begin{array}{l}\text { N0 } \\
50(11.8)\end{array}$ & $\begin{array}{l}\mathrm{N} 1 \\
135(31.8)\end{array}$ & $\begin{array}{l}\mathrm{N} 2 \\
239(56.4)\end{array}$ & $p$ value & $\begin{array}{l}\text { First Echelon } \\
248 \text { (58.5) }\end{array}$ & $\begin{array}{l}\text { Second Echelon } \\
126(29.7)\end{array}$ & $p$ value \\
\hline \multicolumn{8}{|l|}{$\operatorname{Sex}$} \\
\hline Female & $21(42.0)$ & $63(46.7)$ & $112(46.9)$ & $0.815^{*}$ & $134(54.0)$ & $65(51.6)$ & $0.738^{*}$ \\
\hline Male & $29(58.0)$ & $72(53.3)$ & $127(53.1)$ & $1.000^{+}$ & $114(46.0)$ & $61(48.4)$ & $0.735^{\circ}$ \\
\hline \multicolumn{8}{|l|}{ Age $(y r)$} \\
\hline$\leq 65$ & $22(44.0)$ & $63(46.7)$ & $118(49.4)$ & $0.743^{*}$ & $122(49.2)$ & $59(46.8)$ & $0.767^{*}$ \\
\hline$>65$ & $28(56.0)$ & $72(53.3)$ & $121(50.6)$ & $0.693^{+}$ & $126(50.8)$ & $67(53.2)$ & $0.746^{\circ}$ \\
\hline \multicolumn{8}{|l|}{$B M I$} \\
\hline$<25$ & $31(62.0)$ & $82(60.7)$ & $147(61.5)$ & & $155(62.5)$ & $74(58.7)$ & \\
\hline $25-29$ & $15(30.0)$ & 39 (28.9) & $76(31.8)$ & & $75(30.2)$ & $40(31.7)$ & \\
\hline$>29$ & $4(8.0)$ & $10(7.4)$ & $12(5.0)$ & $0.782^{*}$ & $12(4.8)$ & $10(7.9)$ & $0.774^{*}$ \\
\hline Missing & $0(0)$ & $4(3.0)$ & $4(1.7)$ & $0.626^{+}$ & $6(2.4)$ & $2(1.6)$ & $0.596^{\circ}$ \\
\hline \multicolumn{8}{|l|}{ ASA score } \\
\hline 1 & $0(0)$ & $8(5.9)$ & $14(5.9)$ & & $13(5.2)$ & $9(7.1)$ & \\
\hline 2 & $41(82.0)$ & 97 (71.9) & $182(76.2)$ & $0.364^{*}$ & $193(77.8)$ & $86(68.3)$ & $0.114^{*}$ \\
\hline 3 & $9(18.0)$ & $30(22.2)$ & $43(18.0)$ & $0.605^{+}$ & $42(16.9)$ & $31(24.6)$ & $0.132^{\circ}$ \\
\hline \multicolumn{8}{|c|}{ Preoperative pain } \\
\hline No & $42(84.0)$ & $113(83.7)$ & $200(83.7)$ & $0.998^{*}$ & $203(81.9)$ & $110(87.3)$ & $0.402^{*}$ \\
\hline Yes & $8(16.0)$ & $22(16.3)$ & $39(16.3)$ & 1.000 & $45(18.1)$ & $16(12.7)$ & $0.230^{\circ}$ \\
\hline \multicolumn{8}{|c|}{ Preoperative jaundice } \\
\hline No & $22(44.0)$ & $38(28.1)$ & $45(18.8)$ & $<0.001^{*}$ & $63(25.4)$ & $20(15.9)$ & $<0.001^{*}$ \\
\hline Yes & $28(56.0)$ & $97(71.9)$ & $194(81.2)$ & $0.051^{+}$ & $185(75.6)$ & $106(84.1)$ & $0.049^{\circ}$ \\
\hline \multicolumn{8}{|c|}{ Unintentional weight loss } \\
\hline No & $25(50.0)$ & $59(43.7)$ & $103(43.1)$ & $0.666^{*}$ & $115(46.4)$ & $47(37.3)$ & $0.166^{*}$ \\
\hline Yes & $25(50.0)$ & $76(53.6)$ & $136(56.9)$ & $0.996^{+}$ & $133(53.6)$ & $79(62.7)$ & $0.118^{\circ}$ \\
\hline \multicolumn{8}{|c|}{ Diabetes mellitus } \\
\hline No & $40(80.0)$ & $104(77.0)$ & $184(77.0)$ & $0.893^{*}$ & $191(77.0)$ & $97(77.0)$ & $0.893^{*}$ \\
\hline Yes & $10(20.0)$ & $31(23.0)$ & $55(23.0)$ & $1.000^{+}$ & $57(23.0)$ & $29(23.0)$ & $1.000^{\circ}$ \\
\hline \multicolumn{8}{|c|}{ Postoperative complications } \\
\hline No & $21(42.0)$ & $60(44.4)$ & $108(45.2)$ & $0.918^{*}$ & $106(42.7)$ & $62(49.2)$ & $0.457^{*}$ \\
\hline Yes & $29(58.0)$ & $75(55.6)$ & $131(54.8)$ & $0.976^{+}$ & $142(57.3)$ & $64(50.8)$ & $0.281^{\circ}$ \\
\hline \multicolumn{8}{|l|}{$R$-status } \\
\hline R0 & $42(84.0)$ & $88(65.2)$ & $103(43.1)$ & $<0.001^{*}$ & $143(57.7)$ & $48(38.1)$ & $<0.001^{*}$ \\
\hline R1 & $8(16.0)$ & $37(34.8)$ & $136(56.9)$ & $<0.001^{+}$ & $105(42.3)$ & $78(61.9)$ & $0.001^{\circ}$ \\
\hline \multicolumn{8}{|l|}{ Tumor grade } \\
\hline G1 & $3(6.0)$ & $7(5.2)$ & $6(2.5)$ & & $9(3.6)$ & $4(3.2)$ & \\
\hline G2 & $33(66.0)$ & $89(65.9)$ & $148(61.9)$ & & $167(67.3)$ & $70(55.6)$ & \\
\hline G3 & $8(16.0)$ & $34(25.2)$ & $71(29.7)$ & $0.125^{*}$ & $59(23.8)$ & $46(36.5)$ & $0.032^{*}$ \\
\hline Others/missing & $6(12.0)$ & $5(3.7)$ & $14(5.9)$ & $0.333^{+}$ & $13(5.2)$ & $6(4.8)$ & $0.081^{\circ}$ \\
\hline \multicolumn{8}{|c|}{ Perineural invasion } \\
\hline No & $2(4.0)$ & $2(1.5)$ & $1(0.4)$ & $0.095^{*}$ & $3(1.2)$ & $0(0)$ & $0.085^{*}$ \\
\hline Yes & $48(96.0)$ & $133(98.5)$ & $238(99.6)$ & $0.296^{+}$ & $245(98.8)$ & $126(100)$ & $0.554^{\circ}$ \\
\hline \multicolumn{8}{|c|}{ Lymphvascular Invasion } \\
\hline No & $4(8.0)$ & $2(1.5)$ & $0(0)$ & $<0.001^{*}$ & $2(0.8)$ & $0(0)$ & $<0.001^{*}$ \\
\hline Yes & $46(92.0)$ & $133(98.5)$ & $239(100)$ & $0.130^{+}$ & $246(99.2)$ & $126(100)$ & $0.552^{\circ}$ \\
\hline \multicolumn{8}{|c|}{ Peripancreatic fat invasion } \\
\hline No & $10(20.0)$ & $8(5.9)$ & $3(1.3)$ & $<0.001^{*}$ & $9(3.6)$ & $2(1.6)$ & $<0.001^{*}$ \\
\hline
\end{tabular}


TABLE 1 continued

\begin{tabular}{|c|c|c|c|c|c|c|c|}
\hline \multirow[b]{2}{*}{$\begin{array}{l}\text { Parameter } \\
\mathrm{N}(\%)\end{array}$} & \multicolumn{4}{|c|}{ AJCC 8th N-status } & \multicolumn{3}{|c|}{ Site of nodal metastases } \\
\hline & $\begin{array}{l}\text { N0 } \\
50(11.8)\end{array}$ & $\begin{array}{l}\mathrm{N} 1 \\
135(31.8)\end{array}$ & $\begin{array}{l}\mathrm{N} 2 \\
239(56.4)\end{array}$ & $p$ value & $\begin{array}{l}\text { First Echelon } \\
248(58.5)\end{array}$ & $\begin{array}{l}\text { Second Echelon } \\
126(29.7)\end{array}$ & $p$ value \\
\hline Yes & $40(80.0)$ & $127(94.1)$ & $236(98.7)$ & $0.020^{+}$ & $239(96.4)$ & $124(98.4)$ & $0.347^{\circ}$ \\
\hline \multicolumn{8}{|l|}{ T-status } \\
\hline $\mathrm{T} 1$ & $21(42.0)$ & $49(36.3)$ & $46(19.2)$ & & $68(27.4)$ & $27(21.4)$ & \\
\hline $\mathrm{T} 2$ & $25(50.0)$ & $76(56.3)$ & $161(67.4)$ & & $151(60.9)$ & $86(68.3)$ & \\
\hline $\mathrm{T} 3$ & $4(8.0)$ & $8(5.9)$ & $23(9.6)$ & $0.002^{*}$ & $22(8.9)$ & $9(7.1)$ & $0.154^{*}$ \\
\hline Missing & $0(0)$ & $2(1.5)$ & $9(3.8)$ & $0.002^{+}$ & $7(2.8)$ & $4(3.2)$ & $0.526^{\circ}$ \\
\hline \multicolumn{8}{|l|}{$N-$ status } \\
\hline No & NA & NA & NA & NA & - & - & $<0.001^{\circ}$ \\
\hline $\mathrm{N} 1$ & & & & & 118 (47.6) & $17(13.5)$ & \\
\hline $\mathrm{N} 2$ & & & & & $130(52.4)$ & $109(86.5)$ & \\
\hline \multicolumn{8}{|c|}{ No. positive LN stations } \\
\hline 0 & $50(0)$ & - & - & $<0.001^{+}$ & - & - & $<0.001^{\circ}$ \\
\hline 1 & - & $89(65.9)$ & $19(7.9)$ & & $105(42.3)$ & $3(2.4)$ & \\
\hline 2 & - & $41(30.4)$ & $87(36.4)$ & & $108(43.5)$ & $20(15.9)$ & \\
\hline 3 & - & $5(3.7)$ & $62(25.9)$ & & $27(10.9)$ & $40(31.7)$ & \\
\hline$\geq 4$ & - & $0(0)$ & $71(29.7)$ & & $8(3.2)$ & $63(50.0)$ & \\
\hline \multicolumn{8}{|c|}{ Nodal metastases } \\
\hline No & $50(0)$ & - & - & $<0.001^{+}$ & NA & NA & NA \\
\hline First echelon & - & $118(87.4)$ & $130(54.4)$ & & & & \\
\hline Second echelon & - & 17 (12.6) & 109 (45.6) & & & & \\
\hline \multicolumn{8}{|c|}{ Adjuvant treatment } \\
\hline No & $6(12.0)$ & $18(13.3)$ & 28 (11.7) & & 27 (10.9) & $19(15.1)$ & \\
\hline Yes & $44(88.0)$ & $109(80.7)$ & $179(74.9)$ & $0.020^{*}$ & $193(77.8)$ & $95(75.4)$ & $0.109^{*}$ \\
\hline Missing & $0(0)$ & $8(5.9)$ & $32(13.4)$ & $0.080^{+}$ & $28(11.3)$ & $12(9.5)$ & $0.427^{\circ}$ \\
\hline
\end{tabular}

* $p$ value for overall comparisons

${ }^{+} p$ value for $\mathrm{N} 1$ vs. $\mathrm{N} 2$

${ }^{\circ} p$ value for first versus second echelon

(N1/N2) in node-positive patients, and the relative contribution of each nodal station to the number of ELN and PLN are reported in Table 2. The frequency of anatomical stations retrieval from fixed samples ranged from $76.2 \%$ (station 6) to $100 \%$ (station 14), excluding station 5 nodes, which were found in only $7 \%$ of fixed samples and were never metastatic. Hence, this station was excluded from further analyses. Stations with the highest median number of ELN were 13 (9 nodes) and 14 (7 nodes). These also were the most frequent metastatic sites $(77.8 \%$ and $57.5 \%$ respectively).

\section{Survival and Recurrence Analysis}

Survival analysis was performed in 418 patients, after excluding 6 early-censored cases (within 6 months postoperatively). The median follow-up was 26.0 months (IQR 17.2-45.3) in the overall population and 39.4 months $(95 \%$ confidence interval [CI] 23.9-59.6) in censored cases. The median OS was 36.0 months (95\% CI 29.9-42.1). An overview of clinical-pathologic factors associated with survival in the whole study sample is presented in supplementary Table 3A. Univariable analysis of clinicalpathologic factors and nodal-related parameters associated with OS in node-positive patients is shown in supplementary Tables 4A and 3, respectively. Results of the multivariable analyses are summarized in Table 3: N2 
TABLE 2 Nodal yields per anatomical lymph node stations in the overall cohort and correlation with nodal staging (N1/N2) in node-positive patients

\begin{tabular}{|c|c|c|c|c|c|c|}
\hline & $\begin{array}{l}\text { Examined LNs* } \\
\text { median (IQR) }\end{array}$ & $\begin{array}{l}\text { Positive LNs* } \\
\text { median (IQR) }\end{array}$ & $\begin{array}{l}\text { Frequency of harvesting } \\
\text { and station involvement, n(\%) }\end{array}$ & $\begin{array}{l}\mathrm{N} 1 \\
\mathrm{n}(\%)\end{array}$ & $\begin{array}{l}\mathrm{N} 2 \\
\mathrm{n}(\%)\end{array}$ & $\begin{array}{l}p \text { value } \\
(\mathrm{N} 1 \text { vs. } \mathrm{N} 2)\end{array}$ \\
\hline Station 5 & $0.0(0.0-0.0)$ & $0.0(0.0-0.0)$ & $31 / 424(7.3)$ & & & \\
\hline $5-$ & & & $31 / 31(100)$ & $6(100)$ & $21(100)$ & $\mathrm{NC}$ \\
\hline $5+$ & & & 0/31 (0) & $0(0)$ & $0(0)$ & \\
\hline Station 6 & $4.0(1.0-6.0)$ & $0.0(0.0-0.0)$ & $323 / 424(76.2)$ & & & \\
\hline 6- & & & 294/323 (91.0) & $99(98.0)$ & $162(85.7)$ & 0.001 \\
\hline $6+$ & & & 29/323 (9.0) & $2(2.0)$ & $27(14.3)$ & \\
\hline Station 8\# & $2.0(1.0-5.0)$ & $0.0(0.0-0.0)$ & 409/424 (96.5) & & & \\
\hline 8- & & & $344 / 409(84.1)$ & $126(96.9)$ & $168(73.4)$ & $<0.001$ \\
\hline $8+$ & & & $65 / 409(15.9)$ & $4(3.1)$ & $61(26.6)$ & \\
\hline Station $12 \dagger$ & $2.0(1.0-3.0)$ & $0.0(0.0-0.0)$ & $380 / 424(89.6)$ & & & \\
\hline $12-$ & & & $302 / 380(79.5)$ & 107 (89.9) & $148(69.2)$ & $<0.001$ \\
\hline $12+$ & & & $78 / 380(20.5)$ & $12(10.1)$ & $66(30.8)$ & \\
\hline Station 13 & $9.0(6.0-13.0)$ & $2.0(1.0-4.0)$ & 423/424 (99.8) & & & \\
\hline $13-$ & & & $94 / 423(22.2)$ & $33(24.4)$ & $12(5.0)$ & $<0.001$ \\
\hline $13+$ & & & $329 / 423(77.8)$ & $102(75.6)$ & $227(95.0)$ & \\
\hline Station 14 & $7.0(6.0-9.0)$ & $1.0(0.0-3.0)$ & $424 / 424(100)$ & & & \\
\hline $14-$ & & & $180 / 424(42.5)$ & $84(62.2)$ & $46(19.2)$ & $<0.001$ \\
\hline $14+$ & & & $244 / 424(57.5)$ & $51(37.8)$ & $193(80.8)$ & \\
\hline Station 17 & $6.0(3.0-9.0)$ & $0.0(0.0-0.0)$ & $399 / 424(94.1)$ & & & \\
\hline $17-$ & & & $318 / 399$ (79.7) & $114(89.8)$ & $157(69.8)$ & $<0.001$ \\
\hline $17+$ & & & $81 / 399(20.3)$ & $13(10.2)$ & $68(30.2)$ & \\
\hline Jejunal mesentery & $5.0(2.0-8.0)$ & $0.0(0.0-0.0)$ & $373 / 424(88.0)$ & & & \\
\hline Mesentery- & & & $336 / 373(90.1)$ & 113 (96.6) & $178(84.4)$ & 0.002 \\
\hline Mesentery+ & & & $37 / 373$ (9.9) & $4(3.4)$ & $33(15.6)$ & \\
\hline
\end{tabular}

LNs, lymph nodes

*Evaluated in the overall cohort

\#Includes stations 8a-p

$\dagger$ Includes stations 12a-b-p

status, a number of metastatic stations $\geq 4$, metastases to station 14 and jejunal mesentery nodes, but not nodal echelons, were independently associated with survival in each model. The highest concordance was reached in the model including anatomic stations (c-index of 0.769). Survival curves stratified by these nodal-related parameters are shown in Fig. 2.

Information on recurrence site was available in 368 patients $(88.0 \%)$. Of the 249 patients who recurred (67.7\%), 52 experienced an isolated local recurrence (14.1\%), whereas 197 developed distant metastases (53.5\%). The median RFS was 20.7 months (95\% CI 17.723.7). Clinical-pathologic factors associated with recurrence in the whole sample are summarized in supplementary Table 3B. Median RFS of node-positive patients stratified by clinical-pathologic factors and nodalrelated parameters is shown in supplementary Table 4B and Table 4, respectively. Notably, all nodal-related parameters were associated with RFS. The set of multivariable models was replicated for the independent association with disease recurrence: $\mathrm{N} 2$ status, a number of metastatic stations $\geq 4$, metastases to station 14,12 and jejunal mesentery nodes, but not nodal echelons, were independently associated with RFS in each model (Table 5). The highest concordance was again reached in the model including anatomical stations (c-index of 0.709). Analysis of first recurrence site showed and incremental increase in the rate of distant recurrence with increasing nodal involvement, either in terms of PLN, number of positive stations, and nodal echelons (Fig. 3). 
TABLE 3 Univariable analysis of the association between nodal-related parameters $(\mathrm{N}-$ status, lymph node station involvement, number of positive stations and nodal echelon) and survival or recurrence in nodepositive patients

\begin{tabular}{|c|c|c|c|c|}
\hline & $\begin{array}{l}\text { Median overall survival } \\
\text { months }(95 \% \mathrm{CI})\end{array}$ & $p$ value & $\begin{array}{l}\text { Median recurrence-free survival } \\
\text { months }(95 \% \mathrm{CI})\end{array}$ & $p$ value \\
\hline \multicolumn{5}{|l|}{$N$-status } \\
\hline N1 & $49.73(36.79-62.67)$ & 0.001 & $31.000(23.260-38.740)$ & $<\mathbf{0 . 0 0 1}$ \\
\hline $\mathrm{N} 2$ & $26.67(22.77-30.56)$ & & $16.133(12.982-19.284)$ & \\
\hline \multicolumn{5}{|l|}{ Station 5} \\
\hline $5-$ & NA & & NA & \\
\hline \multicolumn{5}{|l|}{$5+$} \\
\hline \multicolumn{5}{|l|}{ Station 6} \\
\hline $6-$ & $32.67(24.58-40.75)$ & 0.066 & $20.00(16.73-23.27)$ & 0.013 \\
\hline $6+$ & $27.133(7.05-47.22)$ & & $13.07(11.87-14.26)$ & \\
\hline \multicolumn{5}{|l|}{ Station $8 *$} \\
\hline $8-$ & $35.23(28.24-42.22)$ & 0.017 & $20.73(16.79-24.67)$ & 0.003 \\
\hline $8+$ & $31.03(17.44-44.62)$ & & $13.80(8.43-19.17)$ & \\
\hline \multicolumn{5}{|l|}{ Station $12 \dagger$} \\
\hline $12-$ & $35.37(27.87-42.86)$ & 0.746 & $20.27(16.34-24.19)$ & 0.140 \\
\hline $12+$ & $31.47(23.30-39.63)$ & & $19.00(15.73-22.27)$ & \\
\hline \multicolumn{5}{|l|}{ Station 13} \\
\hline $13-$ & $36.00(17.95-54.05)$ & 0.332 & $27.17(14.50-39-83)$ & 0.103 \\
\hline $13+$ & $32.73(27.50-37.97)$ & & $18.97(16.69-21.25)$ & \\
\hline \multicolumn{5}{|l|}{ Station 14} \\
\hline $14-$ & $49.73(23.55-75.92)$ & $<0.001$ & $27.43(17.68-37.19)$ & 0.003 \\
\hline $14+$ & $27.40(22.53-32.27)$ & & $17.83(15.11-20.56)$ & \\
\hline \multicolumn{5}{|l|}{ Station 17} \\
\hline $17-$ & $36.00(27.87-44.12)$ & 0.115 & $20.20(16.22-24.18)$ & 0.668 \\
\hline $17+$ & $26.47(20.24-32.69)$ & & $19.00(15.16-22.84)$ & \\
\hline \multicolumn{5}{|c|}{ Jejunal mesentery } \\
\hline Mesentery- & $40.50(32.31-48.69)$ & $<\mathbf{0 . 0 0 1}$ & $21.90(18.60-25.20)$ & $<\mathbf{0 . 0 0 1}$ \\
\hline Mesentery+ & $21.90(15.38-28.41)$ & & $12.00(9.84-14.16)$ & \\
\hline \multicolumn{5}{|l|}{ Nodal metastases } \\
\hline First echelon & $32.73(25.21-40.26)$ & 0.052 & $22.233(16.846-27.621)$ & $\mathbf{0 . 0 1 0}$ \\
\hline Second echelon & $33.40(24.86-41.94)$ & & $16.833(12.096-21.571)$ & \\
\hline \multicolumn{5}{|c|}{ No. metastatic stations } \\
\hline 1 & $73.27(45.52-101.01)$ & 0.001 & $30.43(21.29-39.57)$ & $<\mathbf{0 . 0 0 1}$ \\
\hline $2-3$ & $30.0(25.43-34.58)$ & & $19.10(16.71-21.49)$ & \\
\hline$\geq 4$ & $22.47(15.63-29.30)$ & & $13.07(11.54-14.59)$ & \\
\hline
\end{tabular}

Bold values indicate statistical significance

*Includes stations 8a-p

$\dagger$ Includes stations 12a-b-p

\section{DISCUSSION}

Employing an institutional lymphadenectomy protocol in upfront PD for PDAC, we investigated prospectively the nodal yields per anatomical stations and nodal echelons, and assessed the impact of metastases location on staging, disease recurrence, and survival. Specimen dissection along the right hemi-circumference of the SMA and complete soft tissue clearance along the hepatoduodenal ligament, common hepatic artery and pyloric area resulted in a median of 42 ELN (IQR 34-50), a substantially greater figure relative to other PD series. ${ }^{1-4}$ In turn, this translated to a median number of 4 PLN (IQR 2-8), a rate of nodepositive patients of $88.2 \%$, and a rate of $\mathrm{N} 2$ disease of $56.4 \%$. There was a large variation in the number of ELN for each station and a significant number of cases where no LN were retrieved from certain anatomic locations (i.e., station 5). This is consistent with autopsy studies assessing the number of regional $\mathrm{LN}$ in sites relevant to lymphadenectomy in gastric cancer, showing striking 
(a)

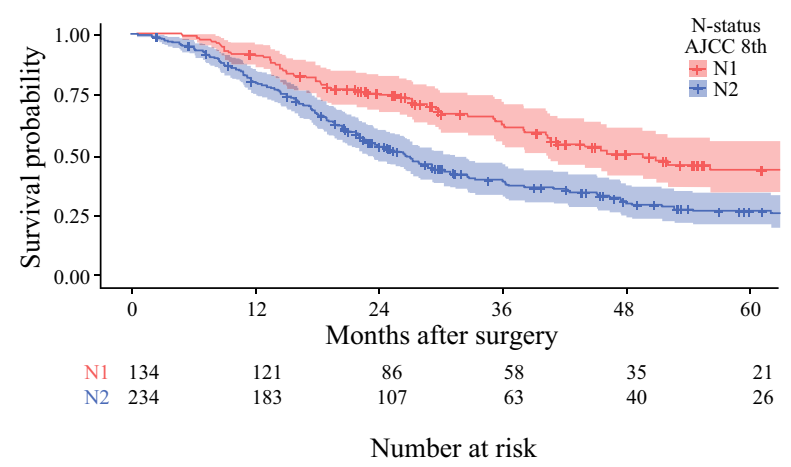

(c)

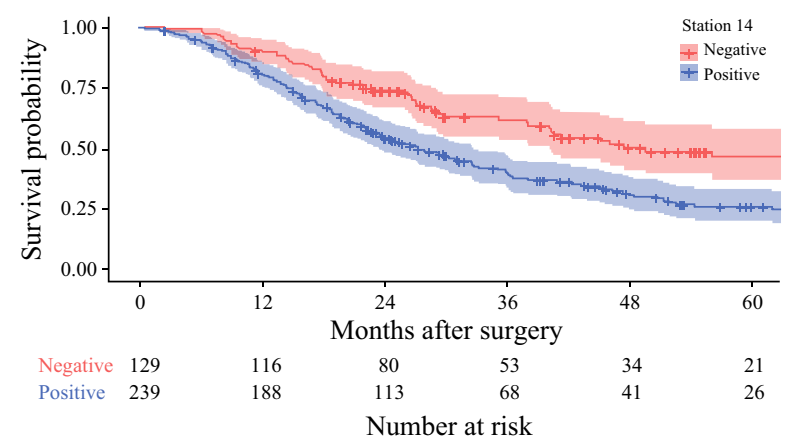

(b)

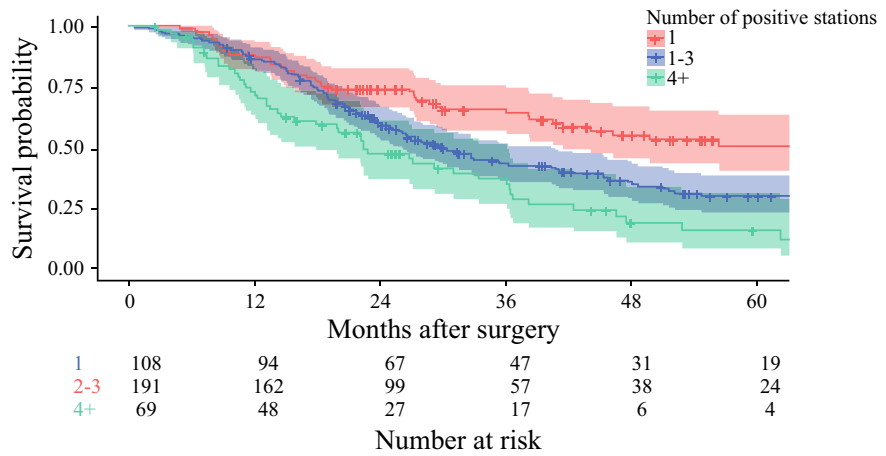

(d)

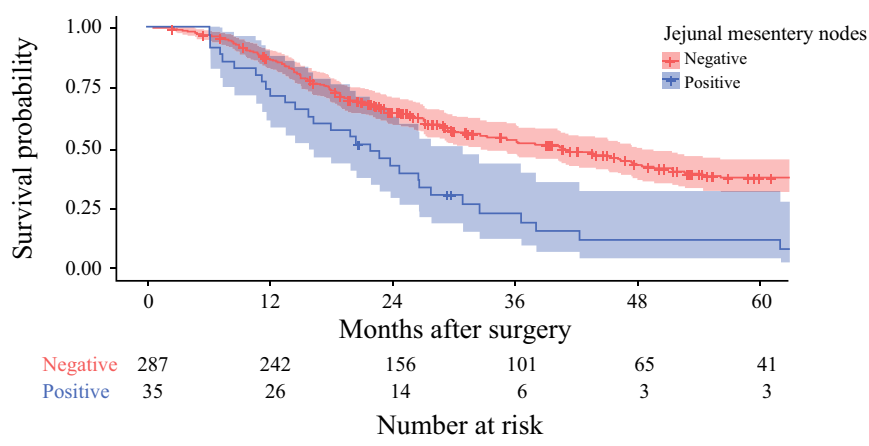

FIG. 2 Kaplan-Meier curves of node-positive patients stratified by N-status (A), number of metastatic stations (B), station 14 (C) and jejunal mesentery node status (D)

individual differences either in the total number of LN and number of single stations. ${ }^{12-14}$ In the present series, nodal metastases most frequently occurred along the SMA groove $(57.5 \%)$ and posteriorly to the pancreatic head (77.8\%), two anatomic stations embedded with the main specimen and thus included in the first nodal echelon. ${ }^{15}$ As per other first-echelon stations, anterior pancreaticoduodenal nodes were metastatic in around $20 \%$ of the cases and — surprisingly—metastases to jejunal mesentery nodes were found in $10 \%$ of patients. Although jejunal mesentery nodes are not included in any PDAC nodal map and the "tail" of the duodenum is normally removed from the specimen before slicing, the jejunal mesentery is routinely included in paraffin blocks by our pathologists, because surgical dissection is conducted along jejunal pedicles and not tangentially to the jejunal loop. Indeed, jejunal lymph nodes are not searched for surgically but found microscopically at the time of pathologic examination.

Overall, the median number of ELN in the first nodal echelon was 28, equaling the optimal threshold for an adequate $\mathrm{N} 2$ staging suggested by a recent joint analysis from the authors' institution and the Massachusetts General Hospital group. ${ }^{5}$ This once again demonstrates that high nodal yields are not necessarily the result of an extended lymphadenectomy, but rather the effect of a thorough pathologic examination with orange-peeling and full inclusion of peripancreatic tissues. ${ }^{16,17}$ The second nodal echelon increased the overall median nodal count by 10 ELN (IQR 6-13). Modeling a staging process with or without the second echelon did not lead to a tangible improvement in nodal classification, as only 18 patients (4.2\%) would have been upstaged adding the second echelon. Nonetheless, the rates of metastases at pyloric nodes, nodes around the common hepatic artery and the hepatoduodenal ligament were $9 \%, 16 \%$, and $21 \%$, resulting in a $30 \%$ aggregate rate of second echelon involvement. This is in sharp contrast with previous studies that analyzed separately second-echelon LN, where approximately only $10 \%$ of patients with resectable PDAC harbored disease at this level. ${ }^{15,18,19}$ Indeed, the concept of second echelon nodes is ill defined in the surgical literature, depending on each institution's nodal dissection policies. In most papers, the second echelon included LN within the retroperitoneum anterior to the inferior vena cava or aorta. This set of nodes was not part of our standard dissection protocol, with station 16a2-b1 being harvested for frozen section analysis in very selected cases, when macroscopically enlarged and/or suspicious. The finding of nodal involvement at this level was considered as distant metastasis, contraindicating the planned resection procedure. ${ }^{20-22}$ Instead, we dissected systematically stations 8a-p and 12a-b-p, because nodes along the common bile duct, hepatic artery, and portal vein 
TABLE 4 Multivariable analysis of factors associated with survival in the subset of node-positive patients

\begin{tabular}{|c|c|c|c|c|c|c|c|c|}
\hline \multirow[t]{2}{*}{ Variables } & \multicolumn{2}{|l|}{$\begin{array}{l}\text { Model } 1 \\
\text { N-status } \\
\text { c-index: } 0.699\end{array}$} & \multicolumn{2}{|l|}{$\begin{array}{l}\text { Model } 2 \\
\text { Lymph node stations } \\
\text { c-index: } 0.769\end{array}$} & \multicolumn{2}{|c|}{$\begin{array}{l}\text { Model } 3 \\
\text { Number of positive stations } \\
\text { c-index: } 0.705\end{array}$} & \multicolumn{2}{|l|}{$\begin{array}{l}\text { Model } 4 \\
\text { Nodal echelons } \\
\text { c-index: } 0.679\end{array}$} \\
\hline & $\begin{array}{l}\text { Hazard ratio } \\
(95 \% \mathrm{CI})\end{array}$ & $p$ value & $\begin{array}{l}\text { Hazard ratio } \\
(95 \% \mathrm{CI})\end{array}$ & $p$ value & $\begin{array}{l}\text { Hazard ratio } \\
(95 \% \mathrm{CI})\end{array}$ & $p$ value & $\begin{array}{l}\text { Hazard ratio } \\
(95 \% \mathrm{CI})\end{array}$ & $p$ value \\
\hline \multicolumn{9}{|c|}{ Vascular resection } \\
\hline No & 1 & & 1 & & 1 & & 1 & 0.020 \\
\hline Yes & $1.626(1.082-2.445)$ & 0.019 & $2.357(1.291-4.305)$ & 0.005 & $\begin{array}{l}1.725 \\
\quad(1.149-2.589)\end{array}$ & 0.009 & $1.603(1.076-2.389)$ & \\
\hline \multicolumn{9}{|c|}{ Tumor grade } \\
\hline G1 & 1 & & 1 & & 1 & & 1 & \\
\hline $\mathrm{G} 2$ & $1.786(0.641-4.975)$ & 0.626 & $3.030(0.507-30.623)$ & 0.233 & $\begin{array}{l}1.834 \\
\quad(0.663-5.077)\end{array}$ & 0.243 & $2.054(0.750-5.622)$ & 0.161 \\
\hline G3 & $\begin{array}{l}4.396 \\
\quad(1.548-10.487)\end{array}$ & 0.005 & $\begin{array}{l}10.182 \\
\quad(1.281-20.933)\end{array}$ & 0.008 & $\begin{array}{l}4.059 \\
\quad(1.435-11.48)\end{array}$ & 0.008 & $\begin{array}{l}4.979 \\
\quad(1.786-12.640)\end{array}$ & 0.002 \\
\hline \multicolumn{9}{|l|}{$N$-status } \\
\hline N1 & 1 & & NA & - & NA & - & NA & - \\
\hline $\mathrm{N} 2$ & $1.958(1.368-2.803)$ & $<0.001$ & & & & & & \\
\hline \multicolumn{9}{|l|}{ Station 14} \\
\hline $14-$ & NA & - & 1 & & NA & - & NA & - \\
\hline $14+$ & & & $2.372(1.384-4.066)$ & 0.002 & & & & \\
\hline \multicolumn{9}{|c|}{ Jejunal mesentery nodes } \\
\hline jejunal- & NA & - & 1 & & NA & - & NA & - \\
\hline jejunal+ & & & $3.927(2.053-7.509)$ & $<0.001$ & & & & \\
\hline \multicolumn{9}{|c|}{ No. positive stations } \\
\hline 1 & NA & - & NA & - & 1 & & NA & - \\
\hline $2-3$ & & & & & $\begin{array}{l}1.476 \\
\quad(0.900-2.422)\end{array}$ & 0.123 & & \\
\hline$\geq 4$ & & & & & $\begin{array}{l}2.449 \\
\quad(1.370-3.693)\end{array}$ & 0.001 & & \\
\hline \multicolumn{9}{|c|}{ Adjuvant treatment } \\
\hline No & 1 & & 1 & & 1 & & 1 & \\
\hline Yes & $0.432(0.279-0.669)$ & $<0.001$ & $0.306(0.175-0.535)$ & $<0.001$ & $\begin{array}{l}0.473 \\
\quad(0.306-0.730)\end{array}$ & 0.001 & $0.508(0.331-0.779)$ & 0.002 \\
\hline
\end{tabular}

are anatomically part of a lymphatic network that rings the pancreas, for which prespecified draining routes have not been identified by anatomical studies. ${ }^{23-25}$ Furthermore, no clear anatomical demarcation lines exist between regions that drain upwards to the hepatoduodenal ligament and downward to the SMA. Besides these anatomical concepts, removal of stations 8 and 12 allows for identification, encirclement, and control of the peripancreatic vasculature during the resection phase, thereby increasing surgical safety especially in the instance of complex vascular dissection. Indeed, extending the dissection beyond the standard boundaries to nearby stations that can be easily incorporated into the resection plane was justified by ISGPS members, with general agreement. ${ }^{8}$ Nonetheless, opponents of systematic nodal dissection in PDAC may still argue that our protocol involves a somewhat "extended" lymphadenectomy, something that has not been associated with improved survival in randomized controlled trials. $^{26,27}$ The present study was not designed to investigate whether retrieval of second-echelon nodes improves survival, because all patients received an identical lymphadenectomy, established a priori. As remarked above, the frequency of second nodal echelon involvement was as high as $30 \%$, with $38 \%$ of these patients receiving a R0 resection, representing $11.3 \%$ of the general population.

On multivariable models, N-status, an increasing number of metastatic stations, and metastases to station 14 and jejunal mesentery nodes were associated with survival. 
TABLE 5 Multivariable analysis of factors associated with recurrence-free survival in the subset of node-positive patients

\begin{tabular}{|c|c|c|c|c|c|c|c|c|}
\hline \multirow[t]{2}{*}{ Variables } & \multicolumn{2}{|l|}{$\begin{array}{l}\text { Model } 1 \\
\text { N-status } \\
\text { c-index: } 0.663\end{array}$} & \multicolumn{2}{|l|}{$\begin{array}{l}\text { Model } 2 \\
\text { Lymph node stations } \\
\text { c-index: } 0.709\end{array}$} & \multicolumn{2}{|c|}{$\begin{array}{l}\text { Model } 3 \\
\text { Number of positive stations } \\
\text { c-index: } 0.661\end{array}$} & \multicolumn{2}{|l|}{$\begin{array}{l}\text { Model } 4 \\
\text { Nodal echelons } \\
\text { c-index: } 0.632\end{array}$} \\
\hline & $\begin{array}{l}\text { Hazard ratio } \\
(95 \% \text { CI })\end{array}$ & $p$ value & $\begin{array}{l}\text { Hazard ratio } \\
(95 \% \text { CI })\end{array}$ & $p$ value & $\begin{array}{l}\text { Hazard ratio } \\
(95 \% \text { CI })\end{array}$ & $p$ value & $\begin{array}{l}\text { Hazard ratio } \\
(95 \% \text { CI })\end{array}$ & $p$ value \\
\hline \multicolumn{9}{|l|}{ T-status } \\
\hline $\mathrm{T} 1$ & 1 & & 1 & & 1 & & 1 & \\
\hline $\mathrm{T} 2$ & $1.680(1.176-2.402)$ & 0.004 & $1.660(0.995-2.772)$ & 0.052 & $1.763(1.232-2.522)$ & 0.002 & $1.664(1.168-2.372)$ & 0.005 \\
\hline $\mathrm{T} 3$ & $2.121(1.168-3.853)$ & 0.014 & $1.146(0.316-4.148)$ & 0.836 & $2.041(1.116-3.733)$ & 0.0210 & $2.261(1.242-4.115)$ & 0.008 \\
\hline \multicolumn{9}{|l|}{$N$-status } \\
\hline N1 & 1 & & NA & - & NA & - & NA & - \\
\hline N2 & $1.572(1.143-2.162)$ & 0.005 & & & & & & \\
\hline \multicolumn{9}{|c|}{ Station $12 *$} \\
\hline $12-$ & NA & - & 1 & & NA & - & NA & - \\
\hline $12+$ & & & $1.896(1.302-1.921)$ & 0.024 & & & & \\
\hline \multicolumn{9}{|l|}{ Station 14} \\
\hline $14-$ & NA & - & 1 & & NA & - & NA & - \\
\hline s14+ & & & $1.774(1.100-2.861)$ & 0.019 & & & & \\
\hline \multicolumn{9}{|c|}{ Jejunal mesentery nodes } \\
\hline jejunal- & NA & - & 1 & & NA & - & NA & - \\
\hline jejunal+ & & & $3.740(1.983-7.054)$ & $<0.001$ & & & & \\
\hline \multicolumn{9}{|c|}{ No. positive stations } \\
\hline 1 & NA & - & NA & - & 1 & & NA & - \\
\hline $2-3$ & & & & & $1.225(0.862-1.742)$ & 0.258 & & \\
\hline$\geq 4$ & & & & & $1.816(1.149-2.871)$ & 0.011 & & \\
\hline \multicolumn{9}{|c|}{ Adjuvant treatment } \\
\hline No & 1 & 0.047 & 1 & 0.001 & 1 & 0.072 & 1 & 0.129 \\
\hline Yes & $0.627(0.395-0.994)$ & & $0.370(0.204-0.671)$ & & $0.656(0.415-1.039)$ & & $0.703(0.445-1.109)$ & \\
\hline
\end{tabular}

*Includes stations 12a-b-p

While the prognostic role of station 14 had been already shown in a previous retrospective analysis of nonconsecutive patients matching the ISGPS lymphadenectomy, ${ }^{11}$ the concept of jejunal mesentery nodal station is novel and of relevance given the 5-year survival rate of only $7.6 \%$ in the instance of its metastatic involvement. Recurrence analysis showed analogous results, adding station 12 to the variable set associated with disease relapse. Interestingly, there was an incremental increase in the rate of distant recurrence in $\mathrm{N} 2$ patients, in those with metastases to second-echelon nodes and in those with and increasing number of metastatic stations, confirming that worsening nodal parameters serve as a proxy of more aggressive disease.

On the ground of these data, we are far from claiming that our lymphadenectomy protocol has a measurable, causative effect on recurrence and survival, although we believe that a diligent nodal dissection serves as an indicator of surgical quality and plays an integral role in the PDAC treatment trajectory, together with multidisciplinary management, patient selection, and access to adjuvant therapy. Remarkably, the median survival rate of 36 months (5-year survival rate of $32.5 \%$ ), and the median recurrence-free survival of 20 months herein reported compare favorably with other contemporary large series. $^{28-30}$

This analysis has several major limitations. The sample size was calculated to estimate the aggregate proportion of nodal metastases in the second echelon, and not the frequency of metastases per single station, thereby requiring regrouping for certain analyses (i.e., stations 8 and 12). Another limitation is that the analysis was done only on patients undergoing upfront $\mathrm{PD}$, and thus these results cannot be extrapolated for those undergoing PD following neoadjuvant treatment. This will be the focus of a separate work. 
FIG. 3 Recurrence status of node-positive patients stratified by nodal echelon involvement (A), nodal status (B), and number of metastatic stations (C) (a) Nodal echelon involvement

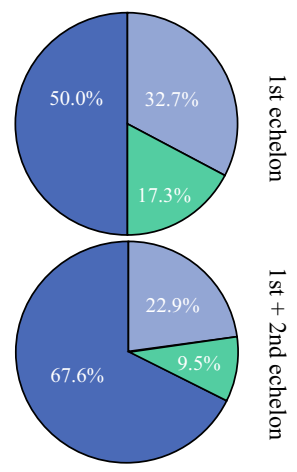

$\mathrm{P}=0.010$ (b) Nodal status (AJCC 8th ed.)

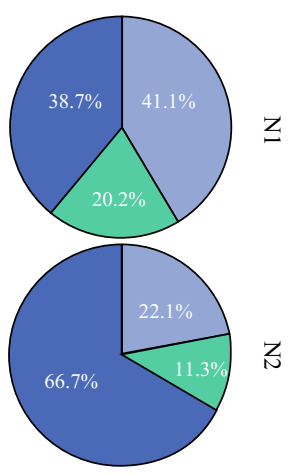

$\mathrm{P}<0.001$ (c) Number of metastatic stations

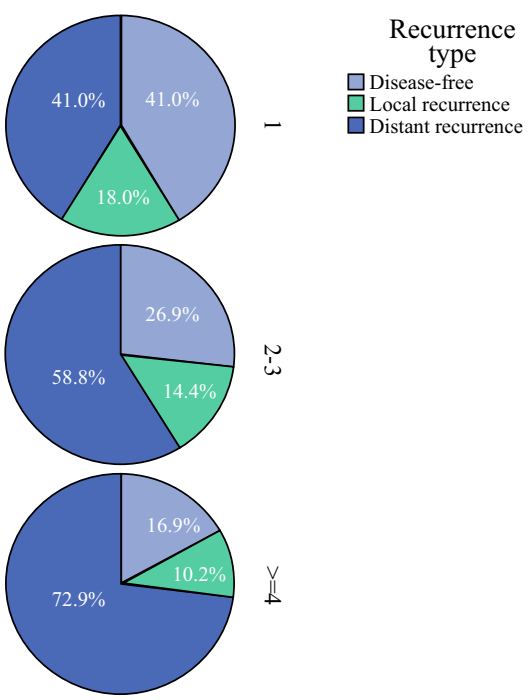

$\mathrm{P}=0.002$

\section{CONCLUSIONS}

Applying a prospective protocol of nodal dissection in upfront PD for PDAC, the overall number of ELN was 42, with a node-positive rate of $88.2 \%$ and a rate of $\mathrm{N} 2$ disease of $56.4 \%$. Nodal metastases occurred more frequently within the surgical specimen, in stations $13(77.8 \%)$ and 14 (57.5\%). The median number of ELN in the first nodal echelon was 28 , demonstrating that an adequate nodal count for optimal staging does not require extended dissection and can be achieved through a diligent pathological examination. Examining nodes in the second echelon does not improve the staging process substantially. Nonetheless, the aggregate frequency of metastases in stations removed as distinct specimens approached $30 \%$, despite metastases in the second echelon did not result to be independently associated with recurrence and survival. Conversely, $\mathrm{N}$-status per the AJCC 8th edition criteria, an increasing number of metastatic stations as well as metastases to station 14 and to jejunal mesentery nodes were prognostically relevant. The jejunal mesentery should be dissected tracing down the first-order jejunal pedicles; and jejunal nodes should be included in the standard nodal map and analyzed pathologically.

Supplementary Information The online version contains supplementary material available at https://doi.org/10.1245/s10434022-11417-3.

OPEN ACCESS This article is licensed under a Creative Commons Attribution 4.0 International License, which permits use, sharing, adaptation, distribution and reproduction in any medium or format, as long as you give appropriate credit to the original author(s) and the

source, provide a link to the Creative Commons licence, and indicate if changes were made. The images or other third party material in this article are included in the article's Creative Commons licence, unless indicated otherwise in a credit line to the material. If material is not included in the article's Creative Commons licence and your intended use is not permitted by statutory regulation or exceeds the permitted use, you will need to obtain permission directly from the copyright holder. To view a copy of this licence, visit http://creativecommons. org/licenses/by/4.0/.

FUNDING Italian Ministry of Health (Grant FIMPCUP_J38D19000690001).

\section{REFERENCES}

1. Strobel O, Hinz U, Gluth A, et al. Pancreatic adenocarcinoma: number of positive nodes allows to distinguish several $\mathrm{N}$ categories. Ann Surg. 2015;261:961-9.

2. Allen PJ, Kuk D, Castillo CF, et al. Multi-institutional validation study of the American Joint Commission on Cancer (8 edn) changes for $\mathrm{T}$ and $\mathrm{N}$ staging in patients with pancreatic adenocarcinoma. Ann Surg. 2017;265:185-91.

3. Amin MB, Edge S, Greene F, et al. AJCC cancer staging manual. 8th edn. New York: Springer; 2018.

4. Van Roessel S, Kasumova GG, Verheij J, Najarian RM, Maggino L, De Pastena M, Malleo G, Marchegiani G, Salvia R, Ng SC, De Geus SW. International validation of the eighth edition of the American Joint Committee on Cancer (AJCC) TNM staging system in patients with resected pancreatic cancer. JAMA Surg. 2018;153(12):e183617

5. Malleo G, Maggino L, Qadan M, et al. Reassessment of the optimal number of examined lymph nodes in pancreatoduodenectomy for pancreatic ductal adenocarcinoma. Ann Surg. 2020. https://doi.org/10.1097/SLA.0000000000004552.

6. Kanda M, Fujii T, Nagai S, et al. Pattern of lymph node metastasis spread in pancreatic cancer. Pancreas. 2011;40:951-5. 
7. Massucco P, Ribero D, Sgotto E, Mellano A, Muratore A, Capussotti L. Prognostic significance of lymph node metastases in pancreatic head cancer treated with extended lymphadenectomy: not just a matter of numbers. Ann Surg Oncol. 2009;16:3323-32.

8. Tol JAMG, Gouma DJ, Bassi C, et al. Definition of a standard lymphadenectomy in surgery for pancreatic ductal adenocarcinoma: a consensus statement by the International Study Group on Pancreatic Surgery (ISGPS). Surgery. 2014;156:591-600.

9. Isaji S, Murata Y, Kishiwada M. New Japanese classification of pancreatic cancer. In: JP Neoptolemos, R Urrutia, JL Abbruzzese, MW Buchler, editors. Pancreatic cancer. 2nd edn. New York: Springer; 2018. p. 1021-37.

10. Malleo G, Maggino L, Marchegiani G, et al. Pancreatectomy with venous resection for $\mathrm{pT} 3$ head adenocarcinoma: perioperative outcomes, recurrence pattern and prognostic implications of histologically confirmed vascular infiltration. Pancreatology. 2017; 17:847-57.

11. Malleo G, Maggino L, Capelli P, et al. Reappraisal of Nodal Staging and Study of Lymph Node Station Involvement in Pancreaticoduodenectomy with the Standard International Study Group of Pancreatic Surgery Definition of Lymphadenectomy for Cancer. J Am Coll Surg. 2015;221:367-79.

12. Bunt AM, Hermans J, van de Velde CJ, et al. Lymph node retrieval in a randomized trial on western-type versus Japanesetype surgery in gastric cancer. J Clin Oncol. 1996;14:2289-94.

13. Herbella FAM, Lourenço LG, Bonini AL, Schlottmann F, Patti MG. Anatomical analysis of gastric lymph nodes in cancer-free individuals. Clin Anat. 2019;32:9-12.

14. Wagner PK, Ramaswamy A, Rüschoff J, Schmitz-Moormann P, Rothmund M. Lymph node counts in the upper abdomen: anatomical basis for lymphadenectomy in gastric cancer. $\mathrm{Br} \mathrm{J}$ Surg. 1991;78:825-7.

15. Pawlik TM, Abdalla EK, Barnett CC, et al. Feasibility of a randomized trial of extended lymphadenectomy for pancreatic cancer. Arch Surg. 2005;140:584-9.

16. Adsay NV, Basturk O, Altinel D, et al. The number of lymph nodes identified in a simple pancreatoduodenectomy specimen: comparison of conventional vs orange-peeling approach in pathologic assessment. Mod Pathol. 2009;22:107-12.

17. Chaudhry IH, Campbell F. An audit of pathology lymph node dissection techniques in pylorus preserving Kausch-Whipple pancreatoduodenectomy specimens. $J$ Clin Pathol. 2001;54:758-61.

18. Yeo CJ, Cameron JL, Sohn TA, et al. Pancreaticoduodenectomy with or without extended retroperitoneal lymphadenectomy for periampullary adenocarcinoma: comparison of morbidity and mortality and short-term outcome. Ann Surg. 1999;229:613-22.

19. Henne-Bruns D, Vogel I, Lüttges J, Klöppel G, Kremer B. Surgery for ductal adenocarcinoma of the pancreatic head: staging, complications, and survival after regional versus extended lymphadenectomy. World J Surg. 2000;24:595-601.

20. Schwarz L, Lupinacci RM, Svrcek M, et al. Para-aortic lymph node sampling in pancreatic head adenocarcinoma. Br J Surg. 2014;101:530-8.

21. Pranger BK, Tseng DSJ, Ubels S, et al. How to approach paraaortic lymph node metastases during exploration for suspected periampullary carcinoma: resection or bypass? Ann Surg Oncol. 2020;27:2949-58.

22. Paiella S, Malleo G, Maggino L, Bassi C, Salvia R, Butturini G. Pancreatectomy with para-aortic lymph node dissection for pancreatic head adenocarcinoma: pattern of nodal metastasis spread and analysis of prognostic factors. $J$ Gastrointest Surg. 2015;19:1610-20.

23. O'Morchoe C. Lymphatic system of the pancreas. Microsc Res Tech. 1997;37:456-77.

24. Cesmebasi A, Malefant J, Patel SD, et al. The surgical anatomy of the lymphatic system of the pancreas. Clin Anat. 2015;28:527-37.

25. Pissas A. Anatomoclinical and anatomosurgical essay on the lymphatic circulation of the pancreas. Anat Clin. 1984;6:255-80.

26. Dillhoff M, Pawlik TM. Role of node dissection in pancreatic tumor resection. Ann Surg Oncol. 2021;28:2374-81.

27. Wang W, He Y, Wu L, et al. Efficacy of extended versus standard lymphadenectomy in pancreatoduodenectomy for pancreatic head adenocarcinoma: an update meta-analysis. Pancreatology. 2019;19:1074-80.

28. Daamen LA, Groot VP, Besselink MG, et al. Detection, treatment, and survival of pancreatic cancer recurrence in the Netherlands: a nationwide analysis. Ann Surg. 2020 Jul 8

29. Strobel O, Lorenz P, Hinz U, et al. Actual five-year survival after upfront resection for pancreatic ductal adenocarcinoma: Who beats the odds? Ann Surg. 2020;267:936-45.

30. Groot VP, Rezaee N, Wu W, et al. Patterns, timing, and predictors of recurrence following pancreatectomy for pancreatic ductal adenocarcinoma. Ann Surg. 2018;267:936-45.

Publisher's Note Springer Nature remains neutral with regard to jurisdictional claims in published maps and institutional affiliations. 